\title{
Saccharomyces boulardii upgrades cellular adaptation after proximal enterectomy in rats
} J-P Buts, N De Keyser, S Marandi, D Hermans, E M Sokal, Y-H E Chae, L Lambotte,
H Chanteux, P M Tulkens

\begin{abstract}
Background-Saccharomyces boulardii is a non-pathogenic yeast which exerts trophic effects on human and rat small intestinal mucosa.

Aims-To examine the effects of $S$ boulardii on ileal adaptation after proximal enterectomy in rats.

Methods-Wistar rats, aged eight weeks, underwent $60 \%$ proximal resection or transection and received by orogastric intubation either $1 \mathrm{mg} / \mathrm{g}$ body wt per day lyophilised $S$ boulardii or the vehicle for seven days. The effects on ileal mucosal adaptation were assessed eight days after surgery.
\end{abstract}

Results-Compared with transection, resection resulted in mucosal hyperplasia with significant decreases in the specific and total activities of sucrase, lactase, and maltase. Treatment of resected animals with $S$ boulardii had no effect on mucosal hyperplasia but did upgrade disaccharidase activities to the levels of the transected group. Enzyme stimulation by $S$ boulardii was associated with significant increases in diamine oxidase activity and mucosal polyamine concentrations. Likewise, sodium dependent $D$-glucose uptake by brush border membrane vesicles, measured as a function of time and glucose concentration in the incubation medium, was significantly $(p<0.05)$ increased by $81 \%$ and three times respectively in the resected group treated with $S$ boulardii. In agreement with this, expression of the sodium/glucose cotransporter-1 in brush border membranes of resected rats treated with $S$ boulardii was enhanced twofold compared with resected controls.

Conclusion-Oral administration of $S$ boulardii soon after proximal enterectomy improves functional adaptation of the remnant ileum.

(Gut 1999;45:89-96)

Keywords: Saccharomyces boulardii; intestine; adaptation; polyamines; brush border membrane enzymes; glucose uptake

After massive small bowel resection, the remnant intestine undergoes an adaptive response that involves both structural and functional changes designed to maintain absorptive capacities. The morphological changes include increased circumference of the intestinal wall and mucosal hyperplasia. ${ }^{1-5}$ Although total disaccharidase activities normalised to gut length increase or remain unchanged compared with sham operated controls, ${ }^{145}$ their specific activities measured in isolated villus cells are considerably decreased, ${ }^{67}$ suggesting that the enhanced hydrolase activity is due to an increased number of cells rather than to increased expression of enzyme molecules per cell. The same is true for nutrient absorption and transport mechanisms, which may increase or remain unchanged mainly as the result of increased mucosal mass rather than because of a net increase in absorptive capacity per enterocyte. ${ }^{89}$ Although the factors governing the adaptation after enterectomy are still poorly understood, oral intake of food has been proved to be a major stimulus. ${ }^{410}$ Nutrients can exert direct trophic effects on intestinal cells and indirect effects mediated by the release of several peptides and trophic hormones. ${ }^{10}$ At the molecular level, a critical event for the onset of mucosal hyperplasia is the synthesis of intracellular polyamines. Inhibition of their rate limiting enzyme, ornithine decarboxylase, by $\alpha$-difluoromethylornithine (DFMO) virtually abolishes the adaptive response to resection, ${ }^{11}$ while administration of aminoguanidine, an inhibitor of the catabolic enzyme diamine oxidase, overstimulates mucosal hyperplasia compared with resected controls. ${ }^{12}$

In human volunteers ${ }^{13}$ and growing rats, ${ }^{13}$ it has been shown that oral treatment with a lyophilised preparation of Saccharomyces boulardii, a non-pathogenic yeast with therapeutic properties, produces trophic intestinal effects including increases in the specific and total activities of brush border membrane (BBM) enzymes, ${ }^{13}$ enhanced secretion of secretory IgA in intestinal fluid, and enhanced production of the receptor for polymeric immunoglobulins in villus and crypt cells. ${ }^{14}$ These trophic effects are, at least in part, mediated by endoluminal release of polyamines, as yeast cells contain substantial amounts of putrescine, spermidine, and spermine totalling $679 \mathrm{nmol} / 100 \mathrm{mg}$ lyophilised preparation. ${ }^{15}$ In addition, the concentrations of polyamines in mucosa and in endoluminal fluid of treated rats were found to be increased in proportion to the amount of spermine and spermidine supplied by the yeast. ${ }^{15}$

In this study, we have extended our observations on $S$ boulardii related effects to an animal model of intestinal resection. Our aim was to characterise early ileal adaptation after $60 \%$

Abbreviations used in this paper: $\mathrm{BBM}$, brush border membrane; SGLT-1, sodium/glucose cotransporter-1; DFMO, $\alpha$-difluoromethylornithine. 
proximal enterectomy in growing rats and to determine whether oral treatment with $S$ boulardii can improve the quality of the adaptive response, implying a potential therapeutic benefit in a situation where upregulation of intestinal nutrient absorption could be advantageous.

\section{Materials and methods}

ANIMAL MODEL

Male Wistar rats, aged eight weeks and weighing 150-155 $\mathrm{g}$, were randomised into transected and resected groups. Animals underwent surgery under ether anaesthesia. The procedure of proximal enterectomy has been described in detail previously. ${ }^{6}$ Briefly, the small intestine was exteriorised through a small midline incision and measured. Starting at 10 $\mathrm{cm}$ distal to the ligament of Treitz, $60 \%$ of the small intestine was resected and an end to end anastomosis was performed about $20 \mathrm{~cm}$ above the ileocaecal valve. In the second group of rats, sham surgery was performed. The ileum was transected at $20 \mathrm{~cm}$ of the ileocaecal valve at the site of anastomosis in animals with resection. After the operation, animals were allowed free access to water. Pellets of food (diet 102; UAR, Villemoisson-sur-Orge, France) were reintroduced 24 hours after surgery. Transected and resected controls were weight and age matched with treated animals and were pair fed, with daily monitoring of food consumption and weight. Resected rats were randomised into two groups. One received by nasogastric intubation a lyophilised preparation of $S$ boulardii (Biocodex Laboratories, Montrouge, France; biological activity 2.4 $\times 10^{9}$ viable cells per $100 \mathrm{mg}$ ) at a dose of 1 $\mathrm{mg} / \mathrm{g}$ body weight per day from day 1 to day 8 after surgery. The second group received by nasogastric intubation an equivalent volume $(0.5 \mathrm{ml})$ of saline according to the same protocol. Day 8 after the operation was chosen for the investigations because at that time mucosal hyperplasia is already distinctly expressed while functional adaptation is depressed per unit of cell $^{69}$ and occurs later on. ${ }^{9}$ Studies were approved by the animal ethics committee of the Catholic University of Louvain, Brussels, Belgium.

PREPARATION OF TISSUES

Animals were weighed daily and observed for vitality and presence of diarrhoea. On day 8 after the operation, the rats were killed by decapitation and the small intestine from the pylorus to the ileocaecal valve was removed and flushed with ice cold saline. The total length was measured under fixed tension $(0.5 \mathrm{~g})$, and it was weighed and opened lengthwise. The mucosa was scraped with glass slides, weighed, immediately wrapped in parafilm and stored at $-170^{\circ} \mathrm{C}$ until use. BBM vesicles were purified from the duodenoileum of transected controls (segment of $40 \mathrm{~cm}$ length) and from the corresponding duodenoileal remnant (segment of $40 \mathrm{~cm}$ length) of resected rats by the calcium chloride precipitation method of Kessler et al. ${ }^{16}$ BBM purity was assessed by recovery of microvillous enzyme activities (sucrase and maltase) in the original homogenate and in the final vesicle pellet. Contamination by basolateral membranes was assessed by measuring $\mathrm{Na}^{+}, \mathrm{K}^{+}$-ATPase activity. ${ }^{17}$ In addition, purity of the samples and morphology of the vesicles were tested by electron microscopy.

BIOCHEMICAL MEASUREMENTS

Sucrase, lactase, and maltase were assayed by the method of Messer and Dahlqvist. ${ }^{18}$ Activities were expressed as $\mu \mathrm{mol}$ of substrate hydrolysed per minute and per g mucosal protein or per mg BBM protein. Protein content in mucosa and BBM was determined by the method of Lowry et al. ${ }^{19}$ DNA was measured by the method of Burton ${ }^{20}$ with the modifications described by Giles and Myers. ${ }^{21}$ Diamine oxidase activity was determined by the method of Okuyama and Kobayashi ${ }^{22}$ using $\left[{ }^{3} \mathrm{H}\right]$ putrescine as substrate, and was expressed as pmol $\Delta^{1}$-pyrroline formed/h per mg protein. Mucosal polyamines (putrescine, spermine, spermidine) were measured by high performance liquid chromatography as previously described, ${ }^{23}$ and concentrations expressed in $\mathrm{nmol} / \mathrm{g}$ mucosa.

D-GLUCOSE UPTAKE

The initial rates of D-glucose uptake in BBM vesicles were measured as a function of incubation time ( 0 to 15 seconds) and D-glucose concentration in the incubation medium $(0.125,0.250,0.500,1,2,4$, and 8 $\mathrm{mM})$.

All uptake studies were carried out by the rapid filtration technique of Hopfer et $a l^{24}$ modified by Johnson et al. ${ }^{25}$ To initiate sodium dependent transport, $50 \mu \mathrm{l}$ freshly prepared vesicles suspended in buffer containing 250 $\mathrm{mM}$ mannitol, $10 \mathrm{mM}$ Hepes, and $10 \mathrm{mM}$ Tris/ $\mathrm{HCl}$ at $\mathrm{pH} 7.5$ were added to $200 \mu \mathrm{l}$ incubation medium containing various concentrations of D-glucose and $\mathrm{D}-\left[{ }^{3} \mathrm{H}\right]$ glucose, $50 \mathrm{mM}$ mannitol, $20 \mathrm{mM}$ Hepes, and $100 \mathrm{mM}$ $\mathrm{NaSCN}$ at $\mathrm{pH} 7.5$. After incubation at $22^{\circ} \mathrm{C}$, the reaction was stopped by the addition of 2 $\mathrm{ml}$ ice cold stop solution containing $20 \mathrm{mM}$ Hepes, $100 \mathrm{mM} \mathrm{NaCl}$, and $150 \mathrm{mM}$ mannitol at $\mathrm{pH}$ 7.5. The combined solution was filtered rapidly through a prewetted $0.45 \mu \mathrm{m}$ nitrocellulose filter (Millipore) and washed three more times with $2 \mathrm{ml}$ of stop solution. Filters were dried and dissolved in scintillation vials containing $10 \mathrm{ml}$ Lumagel and counted. Nonspecific binding of $\left[{ }^{3} \mathrm{H}\right]$ glucose to filters was measured by filtration of incubation medium, stop solution, and vesicles (without mixing incubation medium and vesicles; time 0). All results were subsequently corrected for nonspecific binding. Sodium independent uptake was determined by rapidly mixing $50 \mu \mathrm{l}$ vesicles with $200 \mu \mathrm{l}$ of an incubation medium containing $50 \mathrm{mM}$ mannitol, $20 \mathrm{mM}$ Hepes, $8 \mathrm{mM}$ D-glucose, D- $\left[{ }^{3} \mathrm{H}\right]$ glucose, and $100 \mathrm{mM}$ $\mathrm{KSCN}$, at $\mathrm{pH}$ 7.5. The sodium independent passive component (KSCN) was then subtracted from the total measurements of uptake. The kinetic curves therefore represent only active and sodium dependent specific transport. ${ }^{25}$ Experiments were performed on at least four different fresh vesicle preparations, 
Table 1 Changes in body weight and intestinal variables in transected and resected rats treated with saline or $S$ boulardii

\begin{tabular}{lllll}
\hline Variables & $\begin{array}{l}\text { Transected } \\
\text { controls }\end{array}$ & Resected controls & $\begin{array}{l}\text { Resected treated with } \\
\text { S boulardii }\end{array}$ & $\Delta \%$ \\
\hline Body weight (g) & $150(3.40)$ & $149(3.01)$ & $150(3.57)$ & \\
$\quad$ Day 0 & - & $136(5.62)$ & $137(4.65)$ & \\
$\quad$ Day 4 & $152(1.97)$ & $151(2.85)$ & $150(2.47)$ & \\
$\quad$ Day 8 & $103(1.52)$ & $41.3(1.84)^{\star \star}$ & $42.5(1.27)^{\star \star}$ & -60 \\
Intestinal length (cm) & $127(6.13)$ & $134(4.04)$ & $137(4.6)$ & +8 \\
Mucosal protein $(\mathrm{mg} / \mathrm{g})$ & $5.31(0.25)$ & $12.3(1.14)^{\star \star}$ & $12.8(0.70)^{\star \star}$ & +60 \\
Mucosal protein $(\mathrm{mg} / \mathrm{cm})$ & $6.84(0.41)$ & $6.51(0.15)$ & $6.64(0.29)$ & -3 \\
Protein:DNA ratio & & & \\
\hline
\end{tabular}

Results are expressed as mean $(\mathrm{SEM})(\mathrm{n}=8) . \Delta \%$, variation in percentage $v$ transected controls. ${ }^{\star \star} \mathrm{p}<0.01 v$ non-resected controls.

and the mean was considered as one value for one animal. Uptake data are expressed as nmol D-glucose incorporated per mg BBM protein.

EXPRESSION OF THE SODIUM/GLUCOSE COTRANSPORTER-1 (SGLT-1) IN BBM

The SGLT-1 was detected in BBM from transected and resected rats (treated and controls) by western blot using a monoclonal antibody that recognises the sequence RAYDLFCGLDQD, which corresponds to a cytoplasmic domain of rabbit SGLT-1 (residues 604-615). The rabbit peptide has 95\% homology with the corresponding rat sequence RKAYDLFCGLDQD. The antibody was a gift from Dr E M Wright (Department of Physiol-
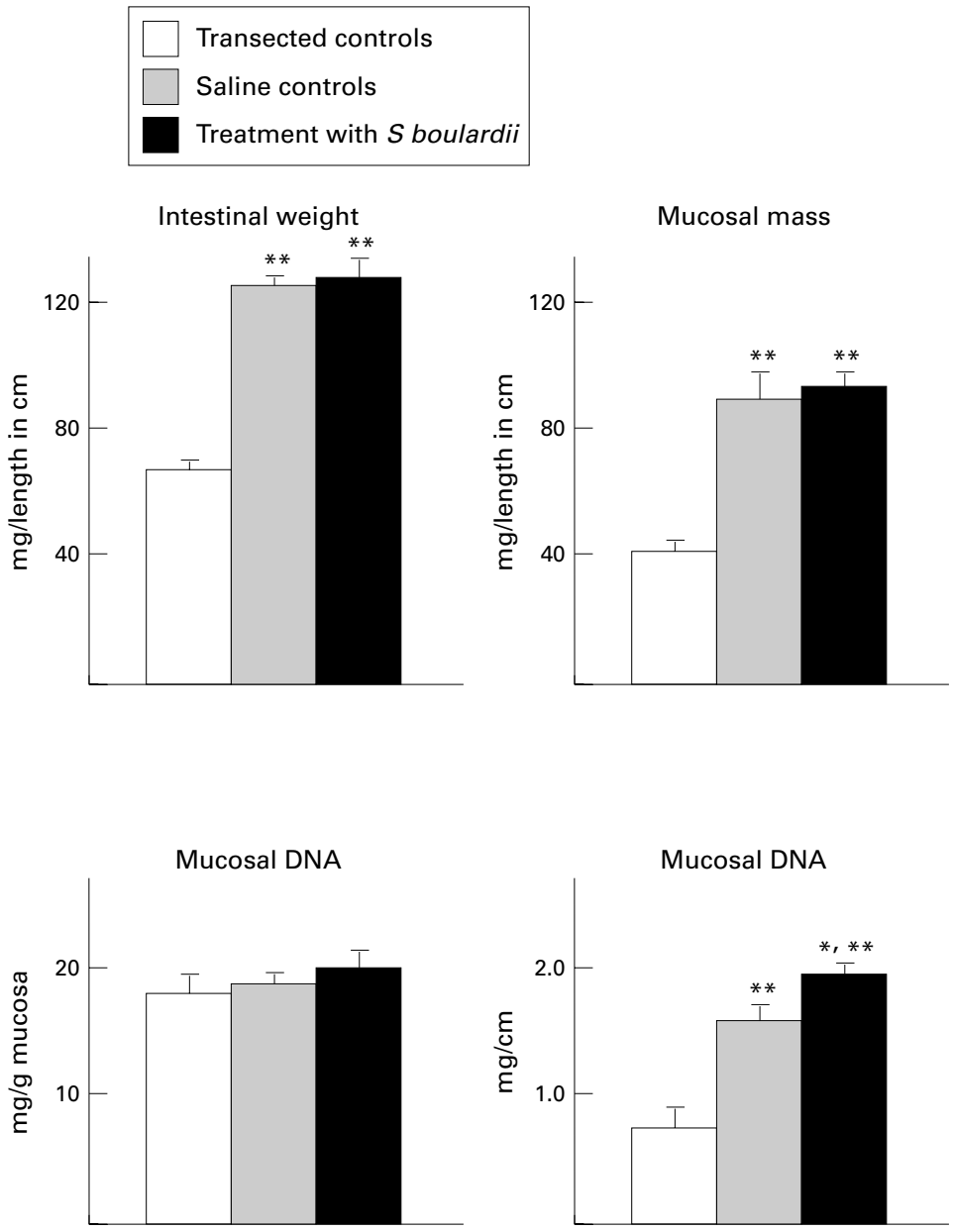

Figure 1 Effect of transection and resection on mucosal mass variables. Values are mean $(S E)$ in transected controls, resected controls treated with saline, and resected rats treated with $S$ boulardii; there were between eight and ten rats in each group. ${ }^{*} p<0.05$ compared with resected control group; ${ }^{\star \star} p<0.01$ compared with transected control group. ogy, University of California, UCLA, Los Angeles, California, USA). After purification of BBM, proteins were separated by one dimensional sodium dodecyl sulphate- $7.5 \%$ polyacrylamide gel electrophoresis using Laemmli's buffer and electrotransferred to polyvinylidene difluoride membranes as described. ${ }^{26}$ Equivalent amounts of BBM vesicles (20 $\mu 1 \mathrm{P}_{2}$ fraction) and $\mathrm{BBM}$ proteins $( \pm 170 \mu \mathrm{g})$ isolated from controls and $S$ boulardii treated rats were loaded on to each gel slot.

Non-specific protein binding was reduced by preincubating the membrane overnight at $4^{\circ} \mathrm{C}$ in a blocking buffer $(5 \%$ bovine serum albumin and $1 \%$ ovalbumin in $10 \mathrm{mM}$ Tris $/ \mathrm{HCl}, \mathrm{pH}$ 7.2, buffer containing $0.9 \% \mathrm{NaCl}$ and $0.02 \%$ $\mathrm{NaN}_{2}$ (buffer A)). The membrane was then incubated with anti-SGLT-1 antibodies, diluted in blocking buffer (1:3000) for two hours at $22^{\circ} \mathrm{C}$ and then washed twice for 10 minutes in buffer $\mathrm{A}$, once for 10 minutes in buffer $\mathrm{A}$ containing $0.05 \%$ Nonidet P40, and twice more for 10 minutes each in buffer $\mathrm{A}$. The blots were then incubated with $50 \mu \mathrm{Ci}$ ${ }^{125} \mathrm{I}$-protein $\mathrm{A}(30 \mu \mathrm{Ci} / \mu \mathrm{g})$ in $10 \mathrm{ml}$ blocking buffer for one hour at $22^{\circ} \mathrm{C}$ and then washed again as described above. Bound anti-SGLT-1 antibodies were detected by autoradiography using Fuji films $(24 \times 30 \mathrm{~cm}$; Fuji, St-Nicolas, Belgium) as described previously. ${ }^{26}$ Gels were calibrated using protein markers of known molecular mass (CFA, Amersham, Bucks, UK). Intensity of signals and relative amounts of proteins detected were compared using a laser imaging densitometer (Bio-Rad; model GS-690). Results were expressed in arbitrary density units (OD) and in density units per surface area $\left(\mathrm{OD} \times \mathrm{mm}^{2}\right)$.

MUCOSAL AND BBM PHOSPHOLIPID CONTENT Total phospholipids from mucosal homogenates and BBMs were extracted as described by Bligh and Dyer $^{27}$ except that the aqueous phase was made acidic with $0.1 \mathrm{M} \mathrm{HCl}$. After mineralisation, phosphorus content was assayed as described by Bartlett. ${ }^{28}$ Total phospholipids were expressed in $\mathrm{nmol} / \mathrm{mg}$ protein. For mucosal homogenates, samples were washed once in Hepes-free medium to remove soluble proteins and interfering components of the buffer. BBM was immediately resuspended in Hepes-free medium after the final pelleting. All assays were carried out in triplicate.

\section{CALCULATIONS AND STATISTICS}

Data are expressed as mean (SE). Mucosal mass variables (weight, DNA, protein) and enzyme activities were also calculated per $\mathrm{cm}$ of intestine (total activity). Differences between means were tested for statistical significance using analysis of variance. When differences were detected, the means of each group were compared using Student's $t$ test or the Mann-Whitney U test if appropriate. Initial rates of glucose uptake were determined by non-linear regression analysis of classical Michaelis-Menten kinetics. 

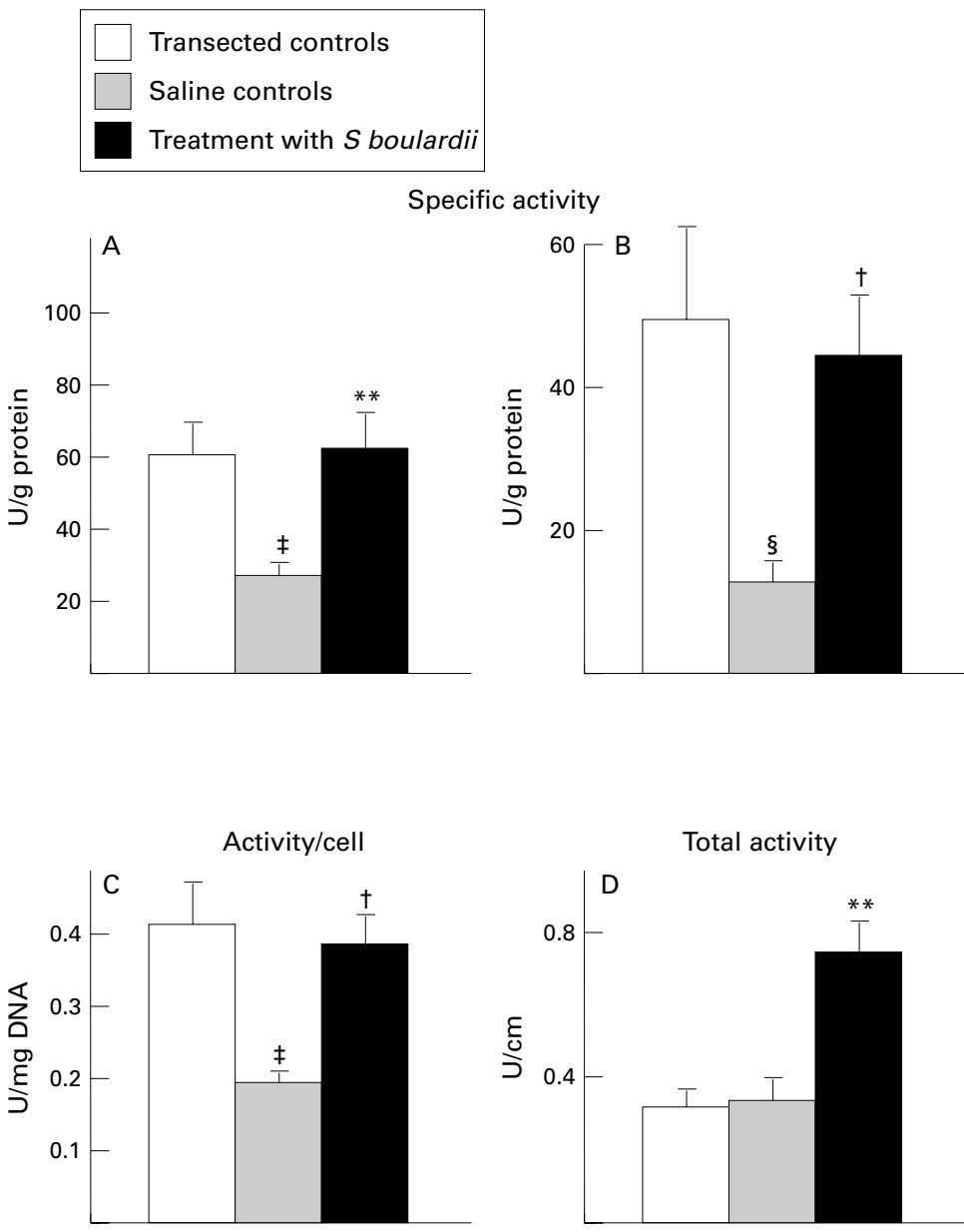

Figure 2 Effect of transection and resection on the specific and total activities of sucrase measured in the proximal segment above the anastomosis $(A, C)$ or in the distal segment below the anastomosis $(B, D)$. Values are mean (SE) in transected controls, resected controls, and resected rats treated with $S$ boulardii; there were at least eight rats in each group. ${ }_{\star *}^{*} p<0.01 v$ resected controls; $+p<0.02 v$ resected controls; $\neq p<0.02 v$ transected controls; $\int p<0.01 v$ transected controls.

\section{Results}

After surgery no animal developed diarrhoea, and the death rate was less than $5 \%$. After eight days of feeding, rats from the three groups appeared healthy. As shown in table 1, initial (day 0) and final (day 8) body weights were equivalent in the transected and resected groups. The length of the remnant ileum was the same in the two resected groups (controls and $S$ boulardii treated) and, as expected, it was $60 \%$ less than the intestinal length measured in the transected group. Compared with transection, resection stimulated mucosal growth appreciably. The intestine appeared to be morphologically increased in both thickness and diameter. Figure 1 and table 1 give the results for mucosal mass. Expressed per $\mathrm{cm}$ of intestine, ileal wet weight, mucosal mass, protein, and DNA content were all significantly increased at day 8 in the resected groups compared with the transected group. There was, however, no difference in these variables between resected rats treated with saline and those treated with $S$ boulardii, except for a small increase in mucosal DNA per cm. Likewise, the protein to DNA ratio remained constant in all the groups (table 1). Also, when results were expressed as mg per total intestine, we found no statistical difference in mucosal mass (resected controls 3510 (902) $v$ treated 3680 (1030); mean (SD)), protein content (507 (108) $v 544(110))$, and DNA content (75 (16) $v 85$ (19)) between resected controls and resected rats treated with $S$ boulardii.

Compared with transection, resection resulted in considerable decreases in the specific and total activities of disaccharidases, and treatment of resected rats with $S$ boulardii upgraded the enzyme activities to the levels measured in transected animals. Figure 2 depicts changes in the specific and total activities of sucrase. Sucrase specific activity whether measured in the ileal segment above the anastomosis (fig 2A) or in the segment distal to the anastomosis (fig $2 \mathrm{~B}$ ) was decreased two- to three-fold in the resected group and increased in the same proportions in response to treatment with $S$ boulardii.

Likewise, the activity of the enzyme, expressed per mg DNA (activity per cell; fig 2C) or per cm of mucosa (total activity; fig 2D), was significantly enhanced in resected rats treated with $S$ boulardii compared with resected controls treated with saline. Figure 3 shows changes in the specific and total activities of lactase and maltase. Lactase specific and total activities (fig 3A,B) were depressed by 4.5 - and 2.5-fold respectively in the remnant ileum of resected rats compared with the activities measured in the equivalent segment of transected rats, while in resected rats treated with $S$ boulardii the enzyme activities were significantly enhanced. Although less pronounced, similar changes were observed for maltase specific and total activities (fig 3C,D). However, there was no difference between resected and transected controls with regard to total maltase activity.

Because yeast cells contain substantial amounts of polyamines which are released during intestinal transit and can stimulate the synthesis of microvillous enzymes after uptake by intestinal cells, ${ }^{15}$ we measured the concentration of putrescine, spermidine, and spermine in the ileal mucosa of transected and resected rats. At day 8 after surgery, spermine and spermidine concentrations were found to be equivalent in the ileal mucosa of transected and resected controls (fig 4). However, resected rats treated with $S$ boulardii exhibited a twofold increase in mucosal putrescine and significant increases in mucosal spermine $(14 \% v$ resected controls; $p<0.05)$ and spermidine $(14 \% v$ resected controls; $\mathrm{p}<0.01)$. Changes in mucosal putrescine metabolism in response to $S$ boulardii treatment were also confirmed by measuring the activity of diamine oxidase, which is proportional to mucosal hyperplasia and peaks in the ileum. ${ }^{29}$ Total diamine oxidase activity was increased twofold in resected rats treated with $S$ boulardii compared with transected controls (table 2). Expressed per mg mucosal protein, the specific activity of the enzyme was $12 \%$ higher $(\mathrm{p}<0.05)$ in resected rats treated with $S$ boulardii than in resected controls.

Table 3 compares the enrichment factors in sucrase specific activity between transected 

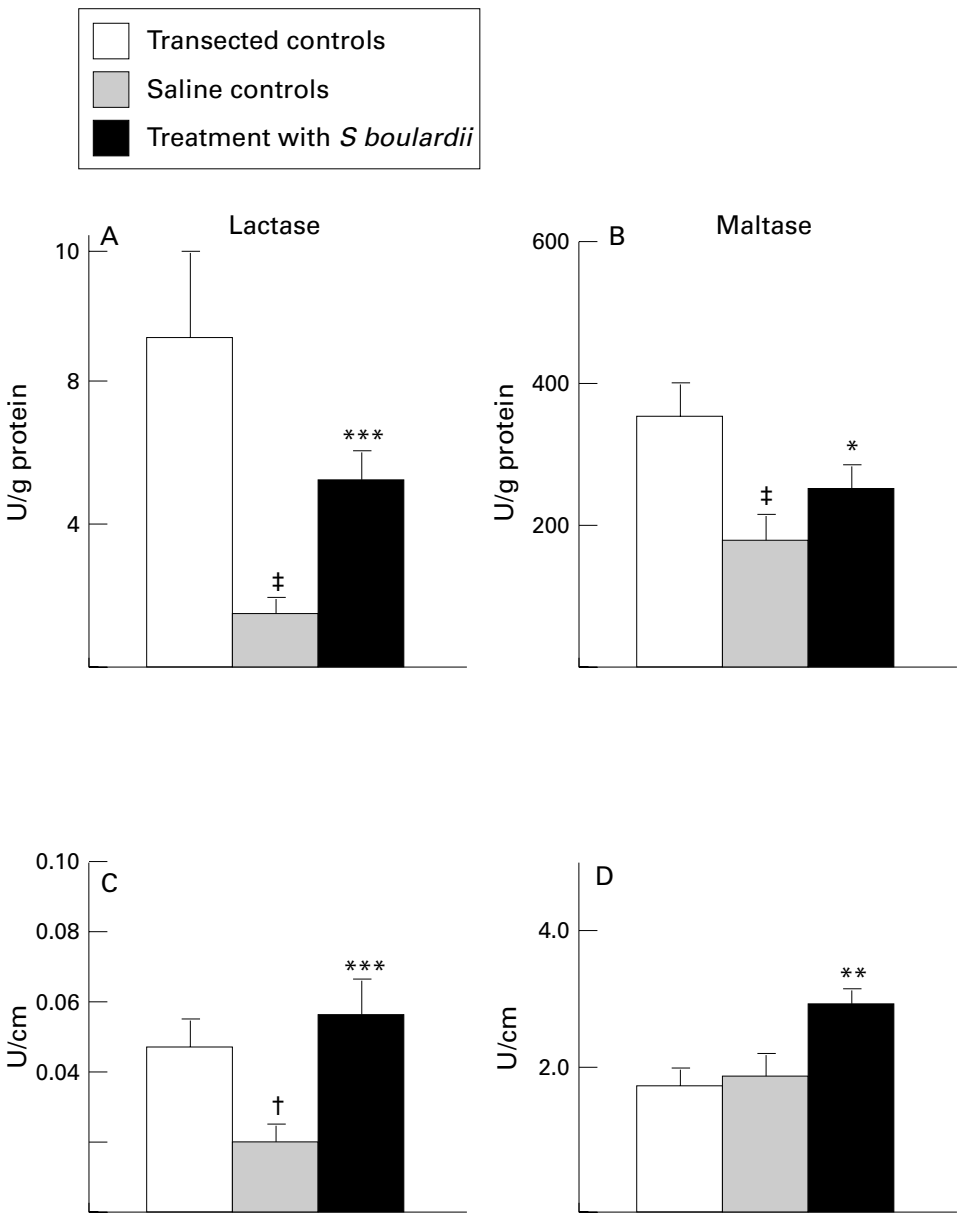

Figure 3 Changes in the specific $(A, C)$ and total $(B, D)$ activities of lactase and maltase in response to transection and resection. Values are mean (SE) in transected controls, resected controls, and resected rats treated with $S$ boulardii; there were at least eight rats in each group. ${ }^{\star \star \star}{ }^{\star} p<0.001 v$ resected controls; ${ }^{\star \star} p<0.01 v$ resected controls; ${ }^{\star} p<0.05 v$ resected controls; $\neq p<0.05 v$ transected controls; $\neq p<0.02 v$ transected controls.

rats, resected controls, and resected rats treated with $S$ boulardii. Enrichment factors in sucrase activity were equivalent between resected controls (12.4) and resected rats treated with
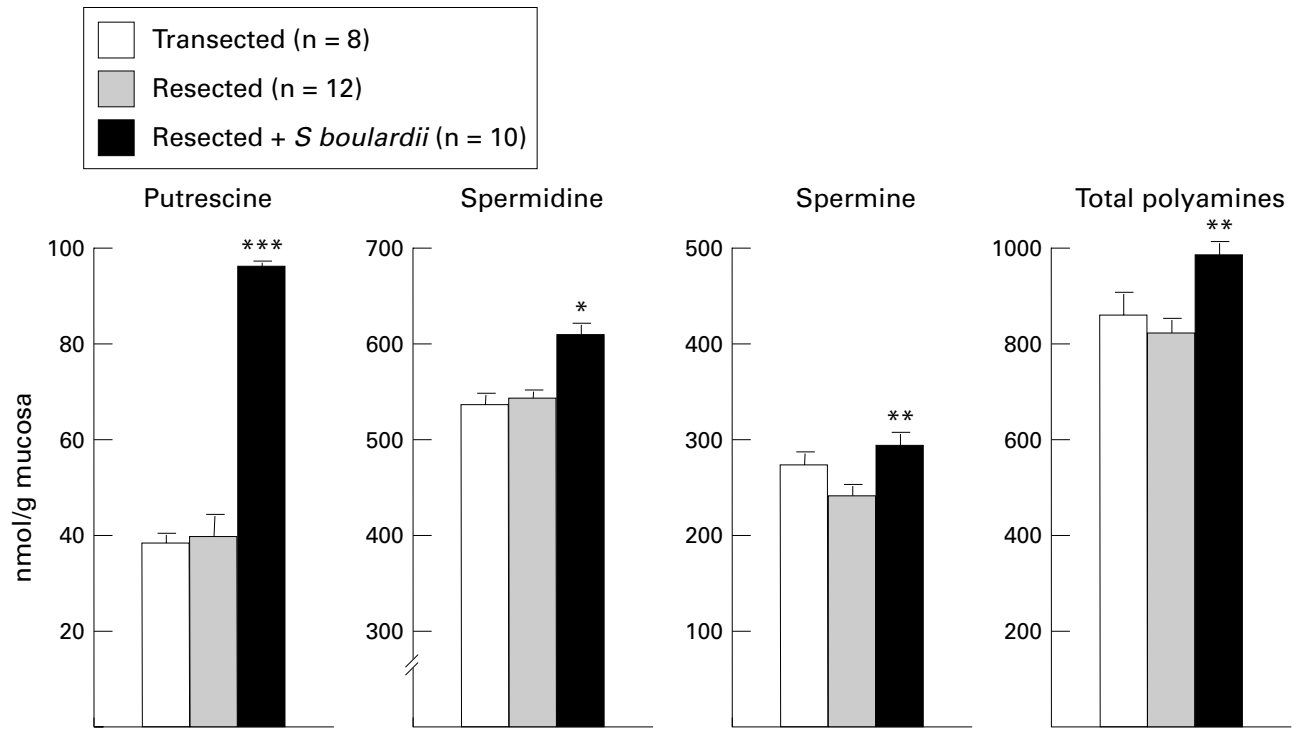

Figure 4 Changes in mucosal polyamine (putrescine, spermidine, spermine) concentration in transected controls $(n=8)$, resected controls $(n=12)$, and resected rats treated with $S$ boulardii $(n=10)$. Values are mean $(S E) .{ }^{* *} p<0.001 v$ transected and resected controls; ${ }^{\star *} p<0.01$ v resected controls; ${ }^{\star} p<0.05 v$ resected controls.
$S$ boulardi (12.0), confirming that the purification procedures performed on comparable intestinal segments yielded vesicles of similar teral membranes was minimal as attested by low $\mathrm{Na}^{+}, \mathrm{K}^{+}$-ATPase activity.

Figure 5 shows the initial rates of sodium dependent D-glucose transport as a function of incubation time. In transected controls, the initial rate of D-glucose uptake was linear up to 15 seconds for both the jejunum and the ileum with, as expected, higher values of transport in the jejunum than in the ileum. Intestinal resection led to a marked decrease in D-glucose uptake, which was linear for up to 5 seconds only, after which time a plateau was reached. In resected animals treated with $S$ boulardii, the uptake rates were significantly enhanced after 5, 10, and 15 seconds of incubation and exceeded by 81,57 , and $47 \%(\mathrm{p}<0.05)$ the values measured in resected controls. Interestingly, the mean value of initial D-glucose uptake measured at five seconds in $S$ boulardii treated rats was almost equivalent to the mean uptake measured in the jejunum of transected controls. As sodium dependent D-glucose uptake was linear for up to five seconds in resected animals, this incubation time was chosen for measurement of initial uptake rates at higher concentrations of glucose in the incubation medium. At $8 \mathrm{mM}$ glucose (fig 5, right), sodium dependent D-glucose uptake was increased three times $(\mathrm{p}<0.05)$ in $S$ boulardii treated rats. The kinetic variables for the initial rates of D-glucose transport were calculated from measurements performed at different concentrations of D-glucose $(0.125$ to $8 \mathrm{mM})$ in the incubation medium (table 4). The maximum transport rate $\left(\mathrm{J}_{\max }\right)$ was significantly enhanced in resected rats treated with $S$ boulardii compared with resected controls, while $\mathrm{K}_{\mathrm{m}}$ values did not change significantly between the three groups. quality. In addition, contamination by basola- 
Table 2 Changes in diamine oxidase activity in the ileal mucosa of transected controls and resected rats treated with saline or with $S$ boulardii

\begin{tabular}{llll}
\hline & Transected controls & Resected controls & $\begin{array}{l}\text { Resected treated with } S \\
\text { boulardii }\end{array}$ \\
\hline nmol/h per g mucosa & $42.7(4.9)$ & $60.5(6.0)^{\star \star}$ & $86.8(11.5)^{\star \star}$ \\
nmol/h per mg protein & $0.372(0.04)$ & $0.464(0.04)^{\star \star}$ & $0.735(0.09)^{\star \star \star \star}$ \\
nmol/h per cm & $1.38(0.21)$ & $3.14(0.61)^{\star \star}$ & $5.56(0.40)^{\star \star}$ \\
\hline
\end{tabular}

Results are expressed as mean (SEM) $(\mathrm{n}=8)$.

${ }^{\star} \mathrm{p}<0.05 v$ resected controls; ${ }^{\star \star} \mathrm{p}<0.01 v$ controls.

Table 3 Specific activity of sucrase and of $\mathrm{Na}^{+}, \mathrm{K}^{+}$-ATPase measured in mucosal homogenates and brush border membranes (BBM) of transected controls, resected controls, and resected rats treated with $S$ boulardii

\begin{tabular}{llll}
\hline & $\begin{array}{l}\text { Transected } \\
\text { controls }\end{array}$ & $\begin{array}{l}\text { Resected } \\
\text { controls }\end{array}$ & $\begin{array}{l}\text { Resected treated } \\
\text { with S boulardii }\end{array}$ \\
\hline Sucrase activity & $59(5.5)$ & $25(1.6)$ & $60(9.1)$ \\
$\quad$ Mucosa (mU/mg mucosal protein) & $601(25)$ & $312(11)$ & $720(30)$ \\
BBM (mU/mg BBM protein) & 10.1 & 12.4 & 12.0 \\
$\quad$ Enrichment factor & - & $0.75(0.1)$ & $0.69(0.1)$ \\
$\mathrm{Na}^{+}, \mathrm{K}^{+}$-ATPase activity (mU/mg BBM protein) & - &
\end{tabular}

Results are expressed as mean (SEM) $(n=6)$.

In agreement with the above results, at day 8 after surgery, expression of SGLT-1, detected in $\mathrm{BBM}$ fractions $\left(\mathrm{P}_{2}\right)$ as a single protein of 75 $\mathrm{kDa}$, was increased twofold (6.30 (0.12) v 3.46 $(0.10) \mathrm{OD} \times \mathrm{mm}$ units, $\mathrm{n}=4)$ in resected rats treated with $S$ boulardii compared with resected controls (fig 6, right). Likewise, expression of SGLT-1 was increased threefold in transected rats treated with $S$ boulardii compared with

Initial uptake
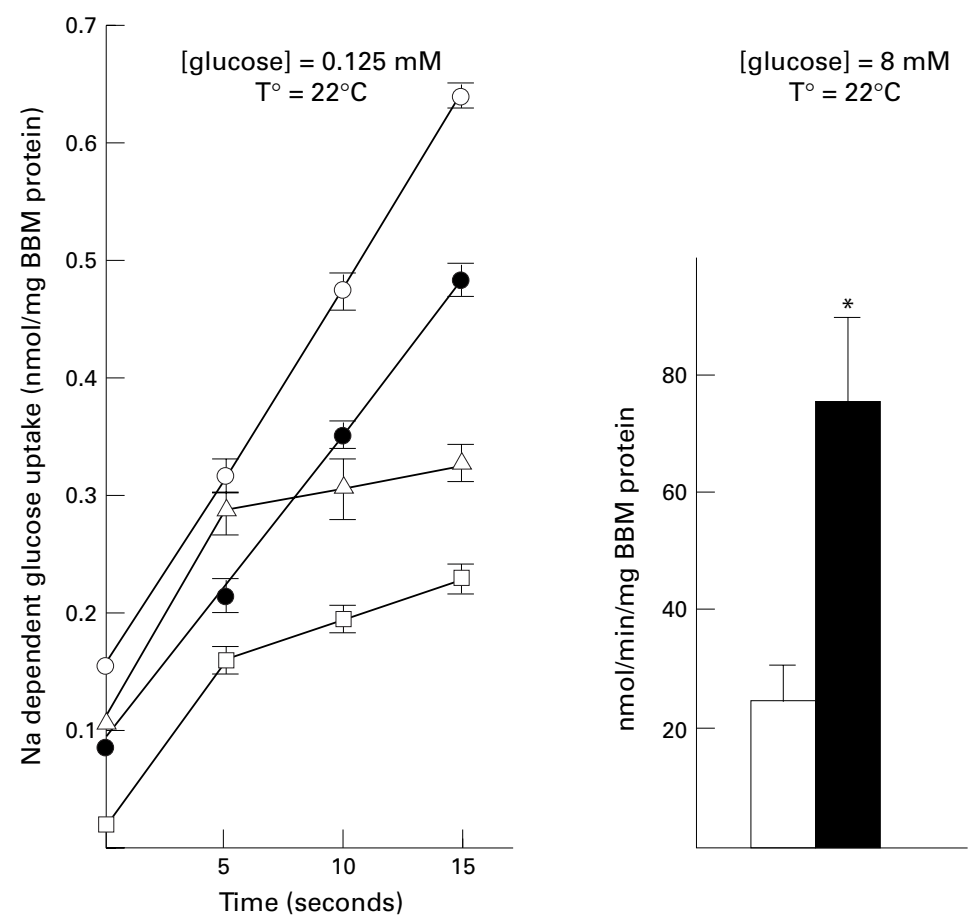

\begin{tabular}{l}
\hline Transected: jejunum \\
$\triangle$ Rransected: ileum \\
$\square$ Resected + S boulardii: remnant ileum \\
\hline
\end{tabular}

Figure 5 Initial rates of sodium dependent glucose uptake as a function of incubation time (left) and high glucose concentration ( $8 \mathrm{mM}$ ) in the medium (right). Data shown are mean (SE) from at least five separate membrane preparations. Each value for glucose uptake is significantly higher in treated resected rats than in resected controls. ${ }^{*} p<0.05 v$ resected controls. transected controls $(22.2(0.19) v 6.48(0.10)$ OD $\times \mathrm{mm}, \mathrm{n}=4$ ) (fig 6 , left).

Total phospholipid content was measured in mucosal homogenates and BBM samples and compared with their protein content. No difference was found between resected controls (n $=5)$ and resected rats treated with $S$ boulardii $(\mathrm{n}=6)$ in phospholipid content of mucosa (102 (5.0) v 105 (2.7) nmol/mg mucosal protein) and BBM (195 (17) v 217 (32) $\mathrm{nmol} / \mathrm{mg} \mathrm{BBM}$ protein).

\section{Discussion}

The results of this study show that the rat ileum undergoes a prompt adaptive response to massive proximal resection. The remnant intestine displayed mucosal hyperplasia eight days after surgery with decreased specific and total disaccharidase activities. Oral treatment of resected rats with $S$ boulardii soon after the operation had no effect on mucosal hyperplasia, which is mainly mediated by the synthesis of intracellular polyamines, ${ }^{11}{ }^{12}$ but caused appreciable stimulation of disaccharidases to activities almost equal to those measured in transected controls.

The other major finding of our study is that sodium dependent glucose transport measured as a function of incubation time and glucose concentration in the incubation medium was significantly enhanced in resected rats by treatment with $S$ boulardii compared with resected controls. The decrease in glucose transport after proximal enterectomy observed here is in agreement with several studies ${ }^{83031}$ showing that early in the period after resection (eight days) mucosal hyperplasia predominates at the expense of enterocyte capacity to absorb nutrients such as glucose and amino acids. This diminution in nutrient absorption capacity per unit of cell is only partially compensated for by the increase in mucosal mass. ${ }^{30}$ Adaptation of absorptive function does in fact occur later. In vitro studies of D-glucose transport in resected animals using either epithelial sheets or BBM vesicles indicate that the increase in transport specific activity occurs only six weeks after surgery. ${ }^{32}$ The factors responsible for upregulating glucose and amino acid absorption are not elucidated, although the adaptation of transport processes appears to be under different mechanisms of control from the mucosal hyperplasia.

Previous studies ${ }^{13} 15$ and the present one provide evidence that $S$ boulardii, when given orally to human volunteers and to normal rats, exerts trophic effects on the small intestine consisting of increases in BBM enzyme activities, cellular concentration of the receptor for polymeric immunoglobulins, ${ }^{14}$ and endoluminal secretion of secretory IgA. ${ }^{14}$ For several reasons, it is believed that these trophic effects are, at least in part, mediated by endoluminal release of polyamines, supplied by the yeast itself. Firstly, $S$ boulardii does not penetrate into enterocytes and can produce similar trophic effects whether given in a viable or a killed form, ${ }^{14}$ suggesting the possible influence of trophic substances secreted by the yeast or released as a result of its catabolism. Although we did not 
Table 4 Kinetic analysis of glucose transport

\begin{tabular}{llll}
\hline & $\begin{array}{l}\text { Transected } \\
\text { controls }\end{array}$ & Resected controls & $\begin{array}{l}\text { Resected treated with } \\
\text { S boulardii }\end{array}$ \\
\hline $\mathrm{J}_{\max }(\mathrm{nmol} / \mathrm{min}$ per mg BBM protein) & $75(13)$ & $23(5.1)$ & $78(11)^{\star}$ \\
$\mathrm{K}_{\mathrm{m}}(\mathrm{mM})$ & $0.170(0.05)$ & $0.154(0.04)$ & $0.168(0.04)$ \\
\hline
\end{tabular}

Results are expressed as mean (SEM) ( $=5)$.

${ }^{\star} \mathrm{p}<0.05 v$ resected controls.

study the faecal colonisation by $S$ boulardii in this model of intestinal resection, a previous study has shown that less than $3 \%$ of the oral dose of yeast cells is recovered in stools in a viable form, ${ }^{33}$ indicating that endoluminal catabolism occurs during intestinal transit. Secondly, our high performance liquid chromatography measurements show substantial amounts of polyamines, totalling $679 \mathrm{nmol} /$ $100 \mathrm{mg}$ lyophilised preparation, mainly spermine and spermidine, which are able to influence directly the synthesis of intestinal glycoproteins and BBM enzymes. ${ }^{34}$ In the present study, resected rats were treated with 1 $\mathrm{mg} / \mathrm{g}$ body weight lyophilised $S$ boulardii, which corresponds to a daily amount of polyamines totalling $1085 \mathrm{nmol}$. This dose is four times higher than the minimal oral dose of spermine or spermidine $(250 \mathrm{nmol})$ needed to enhance intestinal sucrase and maltase activities in normal rats. ${ }^{34}$ Thirdly, after an oral load of polyamines provided by the yeast $(679 \mathrm{nmol})$, spermine and spermidine concentrations were found to be significantly increased in the jejunal and ileal mucosa of treated rats as well as in the endoluminal fluid collected from the jejunum and ileum. ${ }^{15}$ Fourthly, the uptake of endoluminal polyamines by $\mathrm{BBM}$ vesicles is a selective and saturable absorptive process dependent to a large extent on their endoluminal concentration. Finally, inhibition of ornithine decarboxylase activity with DFMO virtually abolishes intestinal adaptation after small bowel resection in rats, ${ }^{11}$ while both enteral and parenteral administration of spermine $\mathrm{s}^{35}$ or precursors such as ornithine $\alpha$-oxoglutarate completely restores or upgrades the early adaptive response to resection. ${ }^{36}$ In addition, microflora derived polyamines can modulate mucosal thickness in an experimental model of intestinal obstruction induced by surgical ligation. ${ }^{37}$

As in normal rats, ${ }^{15}$ mucosal concentrations of polyamines were found to be significantly higher in resected rats treated with $S$ boulardii than in transected and resected controls. The increases in mucosal spermine $(14 \%)$ and spermidine $(14 \%)$ after an oral load of 1085
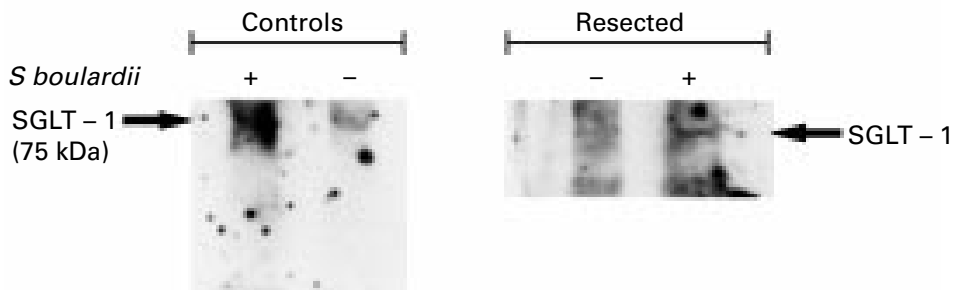

Figure 6 Expression of sodium/glucose cotransporter-1 (SGLT-1) in brush border membrane (BBM) of control rats treated with saline or $S$ boulardii (left) and in BBM of resected rats treated with saline or $S$ boulardii (right). Equivalent amounts of BBM proteins ( $P_{2}$ fraction, $20 \mu \mathrm{l}, 170 \mu \mathrm{g}$ protein) were layered on to each gel slot and separated by sodium dodecyl sulphate-7.5\% polyacrylamide gel electrophoresis. SGLT-1 was detected as a single band at $75 \mathrm{kDa}$ by western blot using a monoclonal antibody. $\mathrm{nmol}$ are in concordance with the ratio of these substances supplied by the yeast (44 and 54\% respectively) and with the data published by Dufour et al, ${ }^{38}$ who reported a $40 \%$ increase in mucosal spermidine concentration after an oral load of $3000 \mathrm{nmol}$ of this substance. Furthermore, in $S$ boulardii treated rats, the changes measured in total polyamines (fig 4) (190 $\mathrm{nmol} / \mathrm{g}$ mucosa representing $750 \mathrm{nmol}$ per total mucosal mass) are also in concordance with the total amount of polyamines supplied by the yeast (1085 nmol per day) and accounted mostly for by changes in spermidine and spermine concentrations. Nevertheless, the absence of any effect of $S$ boulardii and derived polyamines on mucosal mass variables may appear surprising. It is possible that mucosal cell proliferation rates were already maximal eight days after surgery and that the intracellular synthesis of spermine and spermidine was enhanced so much that the oral doses of yeast cells and derived polyamines were not sufficient to accelerate cell division and proliferation any further.

Using a method similar to the present one to measure sodium dependent glucose transport in normal rabbit BBM vesicles, Johnson et $a^{25}$ showed that the oral administration of DFMO, an irreversible inhibitor of ornithine decarboxylase and of the de novo synthesis of intracellular polyamines, significantly lowered the intestinal transport capacity of glucose. Orogastric administration of spermine, spermidine, or putrescine to DFMO-treated rabbits 24 hours before they were killed completely prevented this decrease. In rabbits receiving only orogastric spermine, glucose transport was significantly increased. In the present study, the stimulation of glucose uptake was further confirmed by the finding that expression of SGLT-1 was enhanced in BBM of resected rats treated with $S$ boulardii compared with resected controls. In addition, there was good concordance between the increase in the sodium dependent glucose uptake measured at $8 \mathrm{mM}$ (three times) and the enhanced expression of the SGLT-1 (two times) in resected rats treated with $S$ boulardii. As for BBM enzymes, expression of SGLT-1 was decreased in resected controls (two times) compared with transected controls and was enhanced in transected rats (three times) in response to treatment.

The changes noted in the $S$ boulardii treated group could result from factors other than polyamines. Food is a major stimulus of mucosal hyperplasia. ${ }^{4}$ However, the influence of food cannot explain the changes observed in enzyme activities and glucose transport because animals were pair fed daily and food consumption was monitored. Furthermore, we cannot exclude the possibility that other underlying mechanisms played a role in the upgraded adaptive intestinal response to $S$ boulardii, especially changes in trophic peptides (insulin-like growth factor I, enteroglucagon) and trophic hormones (insulin). ${ }^{31}$

Taken together, our data indicate that lyophilised $S$ boulardii when given soon after resection exerts trophic effects on the remnant 
ileum consisting of an upgrade of disaccharidase activities and a significant stimulation of glucose uptake. These effects are probably mediated by the endoluminal release of polyamines from the yeast cells. Further studies are warranted to evaluate the effects of $S$ boulardii on intestinal adaptation several(six) weeks after extensive resection, when functional adaptation in the remnant ileum is complete.

This work was supported by grant no 3-4346-95 from the Fonds de la Recherche Scientifique Médicale, FRSM, Belgium and by a grant from the Laboratories Biocodex, Montrouge Paris, France. The authors thank Paul Bernasconi and Bernard Hublot for helpful advice and Dominique Vermeulen for preparation of the manuscript.

1 Dowling RH, Booth CC. Structural and functional changes following small intestinal resection in the rat. Clin Sci 1967;32:139-49.

2 Hanson WR, Osborne JW, Sharp JG. Compensation by the residual intestine after intestinal resection in the rat II. Influence of postoperative time interval. Gastroenterology Influence of po

3 McDermott FT, Roudnew B. Ileal crypt cell population kinetics after $40 \%$ small bowel resection. Autoradiographic studies in the rat. Gastroenterology 1976;70:707-11.

4 Feldmann EJ, Dowling RH, McNaughton J, et al. Effects of oral versus intravenous nutrition on intestinal adaptation after small bowel resection in the dog. Gastroenterology 1976;70:712-19.

5 Weser E, Hernandez MH. Studies on small bowel adaptation in the rat. Gastroenterology 1971;60:69-75.

6 Buts JP, De Keyser N, Dive C. Cellular adaptation of the rat small intestine after proximal enterectomy: changes in microvillous enzymes and in the secretory component of immunoglobulins. Pediatr Res 1987;22:29-33.

7 McCarthy DM, Kim SY. Changes in sucrase, enterokinase and peptide hydrolase after intestinal resection. F Clin Invest 1973;52:942-51.

8 Kwan WC, Quamme GA, Freeman HJ. Sodium-dependent D-glucose transport in brush border membrane vesicles after massive distal small bowel resection in the rat. Gastroafter massive distal small bowel

9 Urban E, Michel AM. Separation of adaptive mucosal growth and transport after small bowel resection. Am $\mathscr{f}$ Physiol 1983;244:G295-300.

10 Williamson RCN. Intestinal adaptation: structural, functional and cytokinetic changes. N Engl f Med 1978;298 1393-9.

11 Luk GD, Baylin SB. Inhibition of intestinal epithelial DNA synthesis and adaptive hyperplasia after jejunectomy in the rat by suppression of polyamine biosynthesis. $\mathcal{7}$ Clin Invest 1984;74:696-704.

12 Rokkas T, Vaja S, Murphy GM, et al. Aminoguanidine blocks intestinal diamine oxidase (DAO) activity and enhances the intestinal adaptive response to resection in the rat. Digestion 1990;46:447-57.

13 Buts JP, Bernasconi P, Van Craynest MP, et al. Response of human and rat small intestinal mucosa to oral administration of Saccharomyces boulardii. Pediatr Res 1986;20:1926.

14 Buts JP, Bernasconi P, Vaerman JP, et al. Stimulation of secretory IgA and secretory component of immunoglobulins in small intestine of rats treated with Saccharomyces boulardii. Dig Dis Sci 1990;35:251-6.

15 Buts JP, De Keyser N, De Raedemaeker L. Saccharomyces boulardii enhances rat intestinal enzyme expression by endoluminal release of polyamines. Pediatr Res 1994;36: $522-7$
16 Kessler M, Acuto O, Storelli C, et al. A modified procedure for the rapid preparation of efficiently transporting vesicles from small intestinal brush border membranes. Biochim Biophys Acta 1978;506:136-54.

17 Mircheff AK, Wright EM. Analytical isolation of plasma membranes of intestinal epithelial cells: identification of $\mathrm{Na}, \mathrm{K}-\mathrm{ATPase}$ rich membranes and the distribution of enzyme activities. F Membr Biol 1976;28:309-33.

18 Messer M, Dahlqvist. A one step ultramicromethod for the assay of intestinal disaccharidases. Anal Biochem 1966;14: $376-92$.

19 Lowry OH, Rosebrough NJ, Farr AL, Randall RJ. Protein measurement with the folin reagent. F Biol Chem 1951;193: 265-75

20 Burton K. A study of the conditions and mechanisms of the diphenylamine reaction for the colorimetric estimation of deoxyribonucleic acid. Biochem f 1956;62:315-23.

21 Giles KW, Myers M. An improved diphenylamine method for the estimation of DNA. Nature 1965;206:93-4.

22 Okuyama T, Kobayashi Y. Determination of diamine oxidase activity by liquid scintillation counting. Arch Biochem Biophys 1961;95:242-50.

23 Buts JP, De Keyser N, De Raedemaeker L, et al. Polyamine profiles in human milk, infant artificial formulas and semielemental diets. F Pediatr Gastroenterol Nutr 1995;21:44-9.

24 Hopfer U, Nelson K, Pennotto J, et al. Glucose transport in isolated brush border membranes from rat small intestine. 7 Biol Chem 1973;248:25-32.

25 Johnson LR, Brockway PD, Madsen K, et al. Polyamines alter intestinal glucose transport. Am f Physiol 1995;268: G416-23.

26 Buts JP, De Keyser N, Marandi S, et al. Expression of insulin receptors and of $60-\mathrm{kDa}$ receptor substrate in rat mature and immature enterocytes. Am f Physiol 1997;273: G217-26.

27 Bligh EG, Dyer WJ. A rapid method of total lipid extraction and purification. Can F Biochem Physiol 1959;37:911-17.

28 Barlett GR. Phosphorus assay in column chromatography. $\mathcal{f}$ Biol Chem 1959;234:466-8.

29 Buts JP, Theys S, De Keyser N, et al. Changes in serum and intestinal diamine oxidase (DAO) activity after proximal enterectomy in rats. Correlation of DAO activity with mucosal mass parameters. Dig Dis Sci 1989;34:1393-8.

30 O'Loughlin E, Winter M, Shun A, et al. Structural and functional adaptation following jejunal resection in rabbits: effects of epidermal growth factor. Gastroenterology 1994; 107:87-93.

31 Williamson RC, Buchholtz TW, Malt RA. Humoral stimulation of cell proliferation in small bowel after transection and resection in rats. Gastroenterology 1978;75:249-54.

32 Freeman HJ, Ellis ST, Johnston GA, et al. Sodiumdependent D-glucose transport after proximal small intestinal resection in rats. Am f Physiol 1988;225:G292-7.

33 Boddy AV, Elmer GW, McFarland LV, et al. Influence of antibodies on the recovery and kinetics of Saccharomyces boulardii in rat. Pharm Res 1991;8:796-800.

34 Buts JP, De Keyser N, Kolanowski J, et al. Maturation of villus and crypt cell functions in rat small intestine: role of dietary polyamines. Dig Dis Sci 1993;38:1091-8.

35 Weser E, Harper AV. Inhibition of ornithine decarboxylase and polyamine biosynthesis abolishes intestinal adaptation after small bowel resection: enteral and intravenous putrescine or spermine restores adaptive growth. In: Dowling RH, Riecken EO, eds. Mechanisms of intestinal adaptation. Lancaster: MTP Press, 1982:65-80.

36 Czernichow B, Nsi-Emvo E, Galluser M, et al. Enteral supplementation with ornithine $\alpha$-ketoglutarate improves the early adaptive response to resection. Gut 1997;40:67-72.

37 Osbourne DL, Seidel ER. Microflora derived polyamines modulate obstruction-induced colonic mucosa hypertrophy. Am 7 Physiol 1989;256:G1049-57.

38 Dufour C, Dandrifosse G, Forget P, et al. Spermine and spermidine induce intestinal maturation in the rat. Gastroenterology 1988;95:112-16. 